\section{A statistical package in BASIC for univariate analysis of variance}

\section{RICHARD DENI, JOSEPHINE LONGO, and JENNIFER WHEELER MAKIN \\ Rider College, Lawrenceville, New Jersey 08648}

This statistical package consists of 20 BASIC programs developed for teaching and research applications. The programs follow closely the procedural steps found in current statistics handbooks (e.g., Bruning \& Kintz, 1977; Linton \& Gallo, 1975) and provide for all necessary preanalysis and postanalysis techniques related to univariate analysis of variance procedures. Data can be input via the user's keyboard, and output is either to the user's terminal or to an optional output file designated by the user for later printing or storage. The programs are well documented and self-instructional.

The package was developed for all systems (minicomputer, microcomputer, etc.) with standard BASIC or advanced BASIC. Output file opening statements are specific to the DECsystem 10 , but modification, if required, is straightforward.

All analysis of variance programs print the standard summary table and tables of means and standard deviations per level of each factor and the interactions, if appropriate. Also, the programs contain the .05-level portion of the relevant statistical table, so that the user can obtain immediate estimated significance levels for $F$ ratios and specific comparison results.

The individual programs in the package are listed below:

(1) XMSDV.BAS calculates mean, standard deviation, and variance for groups of scores.

(2) XINDT.BAS calculates t test for independent means.

(3) XCORT.BAS calculates t test for correlated means.

(4) XFMAX.BAS computes homogeneity of variance statistic for groups of scores.

(5) XANOV1.BAS runs a one-way between-subjects analysis of variance.
(6) XANOV2.BAS runs a two-way (a by b) betweensubjects analysis of variance.

(7) XANOV3.BAS runs a three-way ( $a$ by $b$ by c) between-subjects analysis of variance.

(8) XANOV4.BAS runs a one-way (a by s) withinsubjects analysis of variance.

(9) XANOV5.BAS runs a two-way (a by b by s) within-subjects analysis of variance.

(10) XANOV6.BAS runs a three-way (a by b by c by s) within-subjects analysis of variance.

(11) XANOV7.BAS analyzes a between-within (b-w) two-factor mixed design.

(12) XANOV8.BAS analyzes a between-betweenwithin (b-b-w) three-factor mixed design.

(13) XANOV9.BAS analyzes a between-within-within (b-w-w) three-factor mixed design.

(14) XTUKEY.BAS runs Tukey's (a) test for specific mean comparisons.

(15) XTUKUN.BAS runs Tukey's (a) test for specific comparisons of unconfounded means.

(16) XNEWMN.BAS runs a Newman-Keuls test for specific mean comparisons.

(17) XSCHEF.BAS runs a Scheffé test for specific comparisons.

(18) XDUNC.BAS runs the Duncan's New Multiple Range Test for specific comparisons.

(19) XLSD.BAS runs a least significant difference test for specific comparisons.

(20) XSASS.BAS computes strength of association for any treatment source of variance.

Availability. The program listings are available at no charge from Richard Deni, Psychology Department, Rider College, Lawrenceville, New Jersey $0 \$ 648$.

\section{REFERENCES}

Bruning, J. L., \& Kintz, B. L. Computational handbook of statistics. Glenview, Ill: Scott Foresman, 1977.

Linton, M., \& Gallo, P. S., JR. The practical statistician: Simplified handbook of statistics. Monterey, Calif: Brooks/ Cole, 1975.

(Accepted for publication August 25, 1980.) 